\title{
Two Randomized Controlled Trials of Bacillus Calmette-Guérin Vaccination to reduce absenteeism among health care workers and hospital admission by elderly persons during the COVID-19 pandemic: A structured summary of the study protocols for two randomised controlled trials
}

Thijs ten Doesschate ${ }^{1 * \dagger} \mathbb{D}$, Simone J. C. F. M. Moorlag ${ }^{2 \dagger}$, Thomas W. van der Vaart ${ }^{1}$, Esther Taks ${ }^{2}$, Priya Debisarun ${ }^{2}$, Jaap ten Oever ${ }^{2}$, Chantal P. Bleeker-Rovers ${ }^{2}$, Patricia Bruijning Verhagen ${ }^{1}$, Arief Lalmohamed ${ }^{1}$, Rob ter Heine ${ }^{2}$, Reinout van Crevel $^{2}$, Janneke van de Wijgert ${ }^{1}$, Axel B. Janssen ${ }^{1}$, Marc J. Bonten ${ }^{1}$, Cornelis H. van Werkhoven ${ }^{1 \dagger}$, Mihai G. Netea ${ }^{2+}$ and on behalf of the BCG-CORONA study team\#

\footnotetext{
Abstract

Objectives: The objectives of these two separate trials are: (1) to reduce health care workers (HCWs) absenteeism; and (2) to reduce hospital admission among the elderly during the COVID-19 pandemic through BCG vaccination.

Trial design: Two separate multi-centre placebo-controlled parallel group randomized trials

Participants: (1) Health care personnel working in the hospital or ambulance service where they will take care of patients with the COVID-19 infection and (2) elderly $\geq 60$ years. The HCW trial is being undertaken in 9 hospitals. The elderly trial is being undertaken in locations in the community in Nijmegen, Utrecht, and Veghel, in the Netherlands, using senior citizen organisations to facilitate recruitment.

Intervention and comparator: For both trials the intervention group will be randomized to vaccination with 0.1 $\mathrm{ml}$ of the licensed BCG vaccine (Danish strain 1331, SSI, Denmark, equivalent to $0.075 \mathrm{mg}$ attenuated M. bovis). The placebo group consists of $0.1 \mathrm{ml} 0.9 \% \mathrm{NaCl}$, which is the same amount, and has the same colour and appearance as the suspended BCG vaccine.

\footnotetext{
* Correspondence: t.tendoesschate@umcutrecht.nl

Thiijs ten Doesschate and Simone J. C. F. M. Moorlag shared first authorship.

${ }^{\dagger}$ Cornelis H. van Werkhoven and Mihai G. Netea shared senior authorship.

'University Medical Center, Utrecht, The Netherlands

Full list of author information is available at the end of the article
}

(c) The Author(s). 2020 Open Access This article is licensed under a Creative Commons Attribution 4.0 International License, which permits use, sharing, adaptation, distribution and reproduction in any medium or format, as long as you give appropriate credit to the original author(s) and the source, provide a link to the Creative Commons licence, and indicate if changes were made. The images or other third party material in this article are included in the article's Creative Commons licence, unless indicated otherwise in a credit line to the material. If material is not included in the article's Creative Commons licence and your intended use is not permitted by statutory regulation or exceeds the permitted use, you will need to obtain permission directly from the copyright holder. To view a copy of this licence, visit http://creativecommons.org/licenses/by/4.0/. The Creative Commons Public Domain Dedication waiver (http://creativecommons.org/publicdomain/zero/1.0/) applies to the data made available in this article, unless otherwise stated in a credit line to the data. 
(Continued from previous page)

Main outcomes: (1) Number of days of unplanned work absenteeism in HCWs for any reason which can be continuously measured on a bi-weekly basis, and (2) the cumulative incidence of hospital admission due to documented COVID-19.

Randomisation: Participants will be randomized to BCG vaccine or placebo $(1 ; 1)$ centrally using a computer- based system, stratified by study centre.

Blinding (masking): Subjects, investigators, physicians and outcome assessors are blinded for the intervention. Only the pharmacist assistant that prepares- and research personnel that administers- study medicines are unblinded.

Numbers to be randomised (sample size): (1) The sample size for the first trial is $\mathrm{N}=1500$ HCWs randomised 1:1 to either BCG vaccine $(n=750)$ and placebo $(n=750)$ and (2) The sample size for the second trial is $N=1600$ elderly persons randomised to BCG vaccine $(n=800)$ and the placebo group $(n=800)$.

Trial Status: HCW: version 4.0, 24-04-2020. Recruitment began 25-03-2020 and was completed on the 23-04-2020. Elderly: version 3.0, 04-04-2020. Recruitment began 16-04- 2020 and is ongoing.

Trial registration: The HCWs trial was registered 31-03-2020 at clinicaltrials.gov (identifier: NCT04328441) and registered 20-03-2020 at the Dutch Trial Registry (trialregister.nl, identifier Trial NL8477). The elderly trial was registered 22-04-2020 at the Dutch trial registry with number NL8547.

Full protocol: The full protocols will be attached as additional files, accessible from the Trials website (Additional file 1). In the interest in expediting dissemination of this material, the familiar formatting has been eliminated; this Letter serves as a summary of the key elements of the full protocol.

Keywords: COVID-19, Randomised controlled trial, protocol, BCG-vaccine, Health-Care Workers, Elderly

\section{Supplementary information}

Supplementary information accompanies this paper at https://doi.org/10. 1186/s13063-020-04389-w.

Additional file 1. Full study protocol.

\author{
Acknowledgements \\ We gratefully acknowledge all research personnel for their ongoing help in \\ the conduction of these trials, e.g. research nurses, pharmacy assistants, data \\ management, monitors, and the planning and secretarial support office. The \\ BCG-CORONA Study Team includes: \\ - Canisius Wilhelmina Ziekenhuis, Nijmegen - Andreas Voss \\ - Erasmus Medical Center, Rotterdam - Bart J. A. Rijnders, Stijn Klijn \\ - Hagaziekenhuis, The Hague - Cees van Nieuwkoop \\ - Jeroen Bosch Ziekenhuis, Den Bosch - Angèle Kerckhoffs \\ - Leiden University Medical Center, Leiden - Anna H. Roukens, Vincent P. \\ Kuiper, Jan Pieter R. Koopman \\ - Noordwest Ziekenhuisgroep, Alkmaar - Wim J. A Boersma, Nienke \\ Paternotte \\ - Radboud University Medical Center, Nijmegen - Simone J. C. F. M. Moorlag, \\ Esther Taks, Priya Debisarun, Rob ter Heine, Jaap ten Oever, Chantal P. \\ Bleeker-Rovers, Reinout van Crevel, Mihai G. Netea \\ - Sint Maartenskliniek, Nijmegen - Karin Veerman \\ - University Medical Center Utrecht, Utrecht - Thijs ten Doesschate, Thomas \\ W. van der Vaart, Claudia Recanititi, Patricia Bruijning-Verhagen, Arief \\ Lalmohammed, Janneke van de Wijgert, Axel B. Janssen, Marc J. Bonten, \\ Cornelis $\mathrm{H}$. van Werkhoven
}

\section{Authors' contributions}

The whole study team was involved in the design and conduct of this trial. The first version of the protocol manuscript was written by Thijs ten Doesschate and corrections to this draft were made by all study team members.

\section{Funding}

The funding for these investigator-initiated studies for the BCG injections and the design of the eCRF and the mobile application came from the
UMCU and Radboudumc. The participating centers contributed without financial compensation. The authors received no external funding to prepare this trial protocol and summary.

\section{Availability of data and materials}

The investigators from the UMC Utrecht will have access to the final trial dataset of the HCWs trial and the investigators from the Radboudumc will have access to the final trial dataset of the Elderly trial. For the HCWs trial the full dataset will be made available with online electronic Case Report Form (eCRF) ResearchOnline, and for the Elderly trial with Castor.

\section{Ethics approval and consent to participate}

The HCWs trial was approved on 17-03-2020 by the medical ethics committee of the UMCU with reference number RJ/avd/20/010396. The elderly trial was approved on 9-04-2020 by the medical ethics committee of the Radboudumc with reference number 2020-6347. Local approval was given by all participating centres. Written informed consent to participate in this study was obtained from all participants. For both studies, the ethics committees assessed that the study possesses a negligible risk for subjects.

\section{Consent for publication}

Written informed consent for the publication of these details has been obtained from all participants.

\section{Competing interests}

The authors declare that they have no competing interests.

\section{Author details}

${ }^{1}$ University Medical Center, Utrecht, The Netherlands. ${ }^{2}$ Radboud University Medical Center, Nijmegen, the Netherlands.

Received: 4 May 2020 Accepted: 7 May 2020

Published online: 05 June 2020

\section{Publisher's Note}

Springer Nature remains neutral with regard to jurisdictional claims in published maps and institutional affiliations. 